\title{
BRASIL, SUSTENTABILIDADE, DIREITO COSMOPOLITA ${ }^{1}$
}

\author{
Guilherme Assis de Almeida \\ Doutor em Filosofia do Direito pela Faculdade de Direito \\ da Universidade de São Paulo. Pesquisador-senior \\ licenciado do Núcleo de Estudos da Violência da \\ Universidade de São Paulo. Assessor especial da Secretaria \\ de Estado de Direitos Humanos.
}

Para as meninas do Grupo Hannah Arendt

Resumo:

A cidadania cosmopolita, a transformação da pessoa humana em sujeito de Direito; o direito à hospitalidade que ganha uma forma jurídica concreta por meio do reconhecimento de refugiados são alguns dos itens abordados neste artigo.

Abstract:

The cosmopolitan citizenship, the transformation of the human person in a creditor; the right to the hospitality that earns a concrete juridic form through the recognition of refugees are some of the itens boarded in this article.

Unitermos: Direito Cosmopolita; Direito Internacional dos Refugiados; relatório Brundtland.

"Art. I Todas as pessoas nascem livres e iguais en dignidade e direitos. São dotadas de razão e consciência e devem agir em relação umas às outras com espírito de fraternidade."

(Declaração Universal dos Direitos Humanos 1948)

O art. I da Declaração Universal dos Direitos Humanos de 1948, ao estabelecer que a dignidade da pessoa humana advém do fato do nascimento, inaugura uma nova forma de cidadania (o direito a ter direitos, de Hannah Arendt). De agora em diante, ela não mais se vincula à existência jurídica de uma nacionalidade, mas é

1. O presente artigo mostra de forma breve e sintética algumas conclusões que alcancei, enquanto pesquisador-senior do Núcleo de Estudos da Violência/USP na pesquisa financiada pela FAPESP . intitulada "Teoria Integrada dos Direitos Humanos". A detalhada fundamentação teórica das teses aqui esboçadas está sendo feita no âmbito da pesquisa. Para troca de idéias e sugestões, sempre muito bemvindas: guialme@yahoo.com 
adquirida por meio do mero nascer vivo. A cidadania que tem como pré-requisito a nacionalidade é a cidadania do Estado-Nação, a nova forma de cidadania inaugurada pelo Direito Internacional dos Direitos Humanos (DIDH) pode ser definida como cidadania cosmopolita.

O Direito Internacional dos Refugiados (DIR), uma das três vertentes do Direito Internacional dos Direitos Humanos, é de grande valia para ilustrar a cidadania cosmopolita. De acordo com o art. $1^{\circ}$ da Convenção relativa ao Estatuto dos Refugiados (Convenção de Genebra, 1951), é refugiado todo aquele ou aquela que tem "bem fundado temor de perseguição em razão de: raça, religião, nacionalidade, pertencimento a grupo social ou opinião política". Ocorre a perseguição quando o ser humano tem ameaçado dois de seus "mais mínimos direitos humanos": a vida e a liberdade. A pessoa, uma vez perseguida, apesar de continuar detendo o estatuto jurídico de nacional em seu próprio país, vislumbra dificuldades intransponíveis para o normal exercício da cidadania. Diante disso, o indivíduo vê-se obrigado a deixar seu país de nacionalidade ou residência habitual para buscar asilo em outro país. Se tiver sua condição de refugiado reconhecida por qualquer outro país da comunidade internacional e signatário da Convenção de Genebra, 1951, o ser humano readquirirá o seu mais mínimo direito fundamental, vale dizer: a cidadania. Parece óbvio, mas é importante enfatizar que desta feita o exercício da cidadania terá lugar num país que não é o mesmo país da nacionalidade ou de residência habitual do buscador de asilo. Essa verdadeira alquimia jurídica só se tornou possível graças ao art. I da Declaração de 1948 que afirma - de modo assertivo - a inerente dignidade do ser humano. O exercício da cidadania cosmopolita, surgida no âmbito do DIDH, independe da existência de um vínculo jurídico do cidadão com seu país, já que pode ser exercida em qualquer outro país da comunidade internacional.

Uma das mais importantes novidades teóricas do Direito Internacional Público (DIP), no século XX, foi a transformação da pessoa humana em sujeito de Direito. Essa transformação foi possível graças ao surgimento do DIDH. Até então o Direito Internacional Público (DIP) dizia respeito às relações dos Estados e das Organizações Internacionais entre si. O fato de a pessoa humana possuir direitos próprios, que são oponíveis aos Estados, é a mudança propiciada pelo DIDH. Defendo a tese de que o Direito Internacional dos Direitos Humanos é um "Direito de transição"; ele próprio muda a estrutura do Direito Internacional e inicia a elaboração teórica do Direito Cosmopolita.

No terceiro artigo definitivo para a Paz Perpétua, Kant afirma que "o Direito Cosmopolita deve limitar-se às condições da hospitalidade universal" Kant também define o que entende por hospitalidade: "Fala-se aqui, como nos artigos anteriores, não de filantropia, mas de direito, $e$ hospitalidade significa o direito de um estrangeiro a não ser tratado com hostilidade em virtude a sua vinda ao território de outro" ${ }^{2}$

2. Valho-me aqui da edição: KANT, Immanuel "A Paz. Perpétuct e Outros Optísculos" Trad. Artur Morão Lisboa: Edições 70, 1995. p. 137. 
O direito à hospitalidade deve ser visto de forma ampla, enquanto recepção amável do outro, do diferente, do estrangeiro. Essa recepção realizada de forma amorosa não é um assunto poético estranho ao mundo do Direito. Mas uma imperiosa necessidade para o reconhecimento de qualquer ser humano.

"A maior parte do universo, senão sua quase totalidade, está, pelo contrário, destinada ao caos, á dispersão e à desintegração. Os sujeitos estão, portanto, completaniente perdidos no universo.

Escrevo que o ser-sujeito nasceu num universo físico, que ignora a subjetividade que fez brotar, que abriga e, ao mesmo tempo ameaça. O individuo vivo vive e morre neste universo onde só o reconhecem como sujeito alguns congêneres vizinhos e simpáticos. É, portanto, na comunicação amável que podemos encontraro sentido de nossas vidas subjetivas."

O direito à hospitalidade ganha uma forma jurídica concreta por meio do reconhecimento da condição de refugiado ${ }^{4}$ que é - propriamente - um ato do Direito Cosmopolita, já que se trata da outorga da proteção jurídica de um Estado a um estrangeiro de qualquer parte do Planeta. Nesse reconhecimento, não é levada em conta a qualificação jurídica da pessoa, mas seu pertencimento à espécie humana. O que interessa é proteger a dignidade de sua condição humana.

Analisando o DIDH à luz da Teoria Tridimensional do Direito de Miguel Reale, temos que: a dignidade da pessoa humana é o valor que inspira a criação do DIDH, os campos de concentração do Estado nazista e as bombas atômicas de Hiroshima e Nagasaki são os fatos em virtude dos quais é criado o DIDH e a não-violência é o princípio de organização com uma função diretiva que orienta a criação das normas do Direito Internacional dos Direitos Humanos. ${ }^{5}$

Enquanto direito protetivo, o DIDH visa proteger a dignidade da pessoa humana. Para a efetiva proteção da dignidade é fundamental o exercício da nãoviolência. O ser humano só tem dignidade se se pode desenvolver, transformando aquilo que tem como potencial em realizações concretas ${ }^{6}$. A violência, de forma ampla, pode ser definida como tudo aquilo que impede o desenvolvimento do ser humano.

"A violência é aqui definida como a causa da diferença entre o potencial e o actual, entre o que poderia ter sido e o que é. A violência é o que

3. MORIN, Edgard Computo ergo Sum (a noşão de sujeito) Ciência como Consciência, Rio de Janeiro: Bertrand Brasil, 1998. p. 328

4. Diferentemente da concessão do asilo político, o reconheciınento da condição de refugiado por parte de um Estado é um ato declaratório e não-constitutivo.

5. Para uma detalhada análise dessa questão consulte: ALMEIDA, Guilherme Assis de Direitos Humanos e Não-Violência. São Paulo: Editora Atlas, 2001. Especialınente capítulos I e 2.

6. Para um completo e brilhante estudo dessa questão: SEM, Amartya Desenvolvinento como Liberdade Trad. Laura Teixeira Motta, São Paulo: Companhia das Letras, 2000.

7. GALTUNG, Johan "Violência, Paz e Investigação sobre a Paz" em Teoria das Relą̧ōes Internacionais. BRAILLARD, P. (org.) Lisboa: Fundação Callouste Gulbenkian, 1990. p. 334 
aumenta a distância entre o potencial e o actual e o que impede a diminuição dessa distância."

No estágio crítico atual do planeta Terra e da espécie humana que estamos atravessando, a única forma de desenvolvimento capaz de garantir a continuidade da vida de todos nós e do nosso Planeta é o desenvolvimento sustentável ${ }^{*}$

O conceito de desenvolvimento sustentável surge no Relatório Brundtland (também conhecido como "Nosso Futuro Comum”), em 1986. Todavia, será na Conferência das Nações Unidas sobre Ambiente e Desenvolvimento, realizada no Rio de Janeiro, em 1992, que o termo "desenvolvimento sustentável” aparece pela primeira vez em um documento jurídico: a Declaração do Rio sobre Meio Ambiente e Desenvolvimento, que no seu primeiro princípio assevera:

"Principio 1: Os seres humanos estão no centro das preocupações com o desenvolvimento sustentável. Têm direito a uma vida saudável e produtiva, em harmonia com a natureza."

É imprescindível compreender que hoje o desenvolvimento sustentável é um direito humano inalienável e um princípio do Direito Internacional Público. Sua definição mais sintética e precisa é dada pelo próprio autor do relatório "Nosso Futuro Comum" Go Brundtland: "Desenvolvimento Sustentável é aquele que atende às necessidades do presente sem comprometer a possibilidade de as gerações futuras atenderem as suas próprias necessidades. " O conceito de sustentabilidade tem em seu cerne a não-violência. Desenvolvimento sustentável é, em sua essência, o desenvolvimento não-violento.

Desenvolvimento é um tema essencial para o Brasil. Esclarece-nos Celso Lafer:

"O Brasil, como país de contrastes, como um "Outro Ocidente" com inserção no Terceiro Mundo, vive tanto os problemas de meio-ambiente derivados da pobreza, quanto os da produção industrial moderna. Por isso pôde contribuir para trabalhar a idéia de desenvolvimento sustentável como idéia heurística, que relegitimou conceitualmente o tema do desenvolvimento dentro de uma visão de "tema global" reposicionando sob o signo da cooperação esses aspectos das relações Norte/Sul, no mundo pós-Guerra Fria." "9

Uma comunidade internacional na qual todos seus integrantes desenvolvam-se só tornar-se-á possivel quando a sustentabilidade for a força-motriz de sua atividade econômica.

O Brasil, sede da ECO-92 e um dos participantes mais ativos da Rio +

8. Para uına detalhada análise do Desenvolvimento Sustentável: OLIVEIRA, Silvia Menicucci de "Declaração do Rio de Janeiro sobre Meio Ambiente e Desenvolvimento: desenvolvimento sustentável na perspectiva de innlementação dos Direitos Humanos" em ALMEIDA, Guilherme Assis de e PERRONEMOISÉS Cláudia (Orgs.) Direito Internacional dos Direitos Humanos: Inș̣trumentos Básicos. São Paulo: Editora Atlas, no prelo.

9. LAFER, Celso A Identidade Internacional do Brasil e a Política Externa Brasileira Passado, Presente e Futuro. São Paulo: Perspectiva, 200l. P. 79 e 80. 
10, é o espaço geográfico, que Darcy Ribeiro chamou de "moderna civilização tropical da biomassa", de responsabilidade planetária sem precedentes na efetivação histórica do desenvolvimento sustentável.

A fim de que essa responsabilidade venha a ocorrer, urge que equacionemos o quanto antes nossos mais graves problemas internos: erradicação da pobreza absoluta, redistribuição de renda. Importante saber que o equacionamento de nossos problemas internos dar-se-á concomitantemente com nossa atuação internacional em prol da sustentabilidade.

Apesar da angústia do presente, a natureza do Brasil indica nossas potencialidades para construção de um futuro sustentável.

"Nenhum outro país reúne o mesmo elenco de condições favoráveis para, valendo-se das vantagens naturais do trópico (o sol é e será sempre nosso), exploraro trinômio biodiversidade-biomassas-biotecnologia com o intuito de otimizar, integrados em sistema de produção, os seis usos da biomassa: alimentos humanos, rações animais, bioenergia (substituindo hidratos de carbono por hidrocarbonetos), fertilizantes, materiais de construção e insumos industriais. E para liderar assim, em escala mundial, o processo de invenção de uma civilização moderna de biomassa, ecologicamente correta, herdeira das civilizaçôes tradicionais do vegetal."10

A construção de um futuro sustentável é uma tarefa de tamanha urgência, imprescindibilidade e importância que não pode ficar nas mãos, apenas e tão-somente, dos Estados. É preciso que todos os cidadãos do mundo assumam essa tarefa. A Carta da Terra, documento que enuncia "valores e princípios para um futuro sustentável" e que nesse ano na Rio +10 , em Johanesburgo, poderá ser adotado pela Assembléia das Nações Unidas, compreendeu a magnitude desse problema.

"Necessitamos com urgência de uma visão compartilhada de valores básicos para proporcionar um fundamento ético à comunidade mundial emergente. Portanto, juntos na esperança, afirmamos os seguintes principios, todos interdependentes, visando um modo de vida sustentável como critério comum, através dos quais a conduta de todos os indivíduos, organizações e empresas, governos e instituições transnacionais será guiada e avaliada." (Preâmbulo)

A responsabilidade individual pela concretização dos direitos humanos é um tema que apesar de sempre ter estado presente no DIDH nunca foi colocado de forma tão explicita como no momento atual. Faço referência tanto à aprovação do Estatuto de Roma, documento criador do Tribunal Penal Internacional, que estabelece a responsabilização individual por crimes que violem o Direito Penal Internacional; ao "Manifesto 2000 da UNESCO por uma Cultura de Paz e Não-Violência" e à "Carta da Terra" os quais indicam a responsabilidade dos indivíduos na concretização dos direitos humanos e da sustentabilidade.

Superadas a "fase legislativa" e a "fase de implementação" dos direitos

10. SACHS, Ignacy Quo Vadis, Brasil? em "Brasil um Século de Transformações" WILHEIM, Jorge PINHEJRO, Paulo Sérgio e SACHS, Ignacy. São Paulo: Companhia das Letras, 2001. p. 495. 
humanos, entramos na fase de responsabilização individual. Essa fase aponta caminhos para o incremento da elaboração teórica do Direito Cosmopolita.

A nova cultura que está no bojo da sociedade de informação permitenos - de maneira inédita - a criação de redes de comunicação entre homens e mulheres capazes de constituírem uma verdadeira inteligência coletiva. O projeto "Collective Inteligence" dirigido por Pierre Lévy e promovido pela Universidade de Ottawa, bem como o software "Árvores de conhecimentos" "são exemplos concretos dessa etapa histórica que presenciamos. Essas "comunidades sem fio" são o suporte necessário para a efetivação do Direito Cosmopolita.

Inteligência coletiva, enquanto fundamento. Não-violência como princípio, sustentabilidade enquanto meta, e estabelecimento de uma ética e cultura transnacional e planetária como baliza da ação. Aos poucos... vai delineando-se o Direito Cosmopolita.

Quanto ao estabelecimento de uma cultura trasnacional, o Brasil, por ser um País multiétnico, tem uma enorme contribuição a dar na aprendizagem do convívio das diferenças. Urge que deixemos de ser "desterrados en nossa terra" -no dizer de Sérgio Buarque de Holanda - e que sejamos capazes de ser um exemplo na realização do desenvolvimento sustentável. Para o bem-estar de nosso povo, para conservação do Planeta. Essa vital e inadiável tarefa histórica não será feita sem a participação de cidadãos e cidadãs da Terra-Pátria. Oxalá!

São Paulo, agosto de 2002.

11. Para conhecer as "cirvores de comhecimentos", navegue: www.globenet.org/arbor 